\title{
Forestry and the carbon market response to stabilize climate
}

\author{
Massimo Tavoni ${ }^{\mathrm{a}, *}$, Brent Sohngen ${ }^{\mathrm{b}}$, Valentina Bosetti ${ }^{\mathrm{a}}$

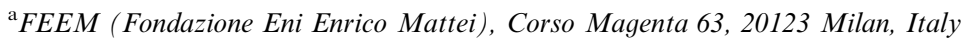 \\ ${ }^{\mathrm{b}}$ Department of Agricultural, Environmental, and Development Economics, Ohio State University, 2120 Fyffe Road, Columbus, OH 43210, USA
}

Received 15 September 2005; accepted 1 January 2006

Available online 30 July 2007

\begin{abstract}
This paper investigates the potential contribution of forestry management in meeting a $\mathrm{CO}_{2}$ stabilization policy of 550 ppmv by 2100 . In order to assess the optimal response of the carbon market to forest sequestration, we couple two global models. An energy-economy-climate model for the study of climate policies is linked with a detailed forestry model through an iterative procedure to provide the optimal abatement strategy. Results show that forestry is a determinant abatement option and could lead to significantly lower policy costs if included. Linking forestry management to the carbon market has the potential to alleviate the policy burden of $50 \mathrm{ppmv}$ or equivalently of $\frac{1}{4}{ }^{\circ} \mathrm{C}$, and to significantly decrease the price of carbon. Biological sequestration will mostly come from avoided deforestation in tropical-forest-rich countries. The inclusion of this mitigation option is demonstrated to crowd out some of the traditional abatement in the energy sector and to lessen induced technological change in clean technologies.
\end{abstract}

(C) 2007 Elsevier Ltd. All rights reserved.

Keywords: Forestry; Climate policy; Technological innovation

\section{Introduction}

This study examines the role that forestry may play in the context of atmospheric $\mathrm{CO}_{2}$ stabilization. There is widespread research suggesting that biological sequestration of carbon can play an important role for reducing greenhouse gases (GHG) emissions through activities such as slowing the rate of deforestation, increasing the establishment of forests on old agricultural or degraded lands, and improving the management of existing and future timber (see, for example, Metz et al., 2001). Estimates of the range of potential costs of sequestration are fairly wide (Richards and Stokes, 2004), but there is also general consensus that forest sinks can be a valuable mitigation option. However, the nations of the Kyoto Protocol have thus far only haltingly incorporated forestry measures, and the Kyoto process only recently (at the 11th Conference of Parties in 2005) began considering how one of the measures with the largest potential, tropical forest conservation or prevention of deforestation (see, for this

\footnotetext{
*Corresponding author. Tel.: + 390252036814 ; fax: + 390252036946.

E-mail address: massimo.tavoni@feem.it (M. Tavoni).
}

purpose, the proposal as in Moutinho et al., 2005) could be included.

There are several explanations for the limited role that forestry has so far played in abatement strategies. First, error bounds for measuring and monitoring carbon in forests are fairly large in developed countries with wellestablished measurement technologies (see Watson et al., 2000). Errors in calculating carbon storage are likely to be larger in developing countries that have devoted fewer resources to conducting forest inventories. Second, many concerns have been raised about issues such as additionality and permanence. Unlike abatement of energy emissions, carbon stored in forests is subject to future emissions due to harvesting or other natural disturbances. Third, it is widely assumed that allowing forestry options would reduce incentives to develop important abatement technologies, and these technologies are ultimately necessary to achieve a stable, albeit changed, climate. The first two questions have been widely addressed in a range of publications, including those of the Intergovernmental Panel on Climate Change (see Watson et al., 2000; Metz et al., 2001). However, no one has yet quantified the implications of a forest carbon 
sequestration program on the innovation of energy abatement technologies.

Recent research indicates that global policies meant to stabilize GHG concentrations in the future will require a vast bundle of measures to meet ambitious targets (Pacala and Socolow, 2004). Given the recent focus on stabilization policies and the apparent costs of achieving fairly stringent concentration targets, it is surprising that relatively few energy models have even incorporated forestry sequestration (see Rose et al., 2006). Sohngen and Mendelsohn (2003), do link a forestry model to an aggregate global climate - economy model (DICE; Nordhaus and Boyer, 2000), and their results suggest that forestry could provide nearly one-third of the world's carbon abatement over the coming century, but that study examined a fairly limited overall carbon abatement strategy, and it suggested that a large portion of the carbon sequestration in forests would occur later in the century (thus having little impact on energy abatement). With more stringent policies, carbon prices initially are expected to be higher, and forestry sequestration could have more important implications for the costs of the overall abatement program.

This paper develops an intertemporal optimization model of carbon abatement in the energy and land-using sectors to analyze the potential role that forests may play in climate stabilization policy. To accomplish this, we bring together a forestry and an energy-economy-climate model to evaluate the mitigation potential of forest sequestration and to measure the deriving feedback on "traditional" abatement options and on the carbon market as a whole. To put ourselves in a context of a global climate policy, we consider a target of a 550 ppmv $\mathrm{CO}_{2}$ only stabilization (see International Panel on Climate Change (IPCC) (2001) for a scientific motivation of the target), and examine the abatement pathway with and without forestry sequestration.

Results show that forestry has important implications for the overall abatement strategy, and a profound effect on the carbon market (i.e., on the global costs of a climate policy), so that, for example, 50 additional ppmv-equivalently of $\frac{1}{4}{ }^{\circ} \mathrm{C}$ - are achieved at no extra cost. The numerical optimization estimates that forest sinks can contribute to one-third of total abatement by 2050 and decrease the price of carbon by $40 \%$ by 2050 . This decisive reduction in the policy costs is mainly attained via avoiding deforestation in tropical forests in the first half of the century, though it could also be sustained in later periods by afforestation and enhanced forest management. The introduction of the forestry option is shown to have a visible influence on other abatement alternatives: in meeting a given policy target, forestry crowds out some abatement in the energy sector, so that, for example, improvements of the energy intensity of the economy are more modest in early periods. More importantly, policy-induced technological change in clean technologies such as renewables power generation is also reduced. Although the time needed for technological advancement may be considered as one reason to delay permanent emissions cuts, buying time with forestry appears to be an attractive mitigation option.

In order to produce results, the two world models are coupled via an iterative procedure that focuses on carbon quantities and prices. Various characteristics are at the basis of the originality of the present paper. First, the model's dynamic specification of the economy and the detail of the energy sector allow us to assess the dynamic feedbacks on the economic system as well as the evolution of energy technologies. This enables us to integrate forest carbon sinks into the control problem of GHG mitigation, so that investments in final good, energy technologies, energy R\&D, and forestry are optimally chosen. The energy sector description and the presence of endogenous technological change - a central feature for climate change modeling; see Goulder and Mathai (2000) - puts us in the condition to assess how the inclusion of forestry incentives may affect induced technological change, an issue not yet investigated to our knowledge. Moreover, the intertemporal structure of the models is essential to understand the timing issue of the biological sequestration abatement option, which is a largely discussed one because of the non-permanence issue (managed forests do not sequester carbon permanently but release it back to the atmosphere if harvested).

Second, the regional disaggregation of both models allows us to account for distributional issues among countries (the so-called "where" dimension), an issue that has proved particularly central in the policy debate surrounding the forestry abatement option. Last but not least, contrary to current studies, by framing the analysis in a global mitigation policy context such as a $550 \mathrm{ppmv}$ target, we are able to augment the cost-effectiveness literature introducing an additional measure designed to cover a stabilization wedge.

With respect to the existing literature, the approach that is the closest to ours is the one in Sohngen and Mendelsohn (2003). Their original analysis is, however, limited to a single world region and has incomplete technological detail. Similar to van't Veld and Plantinga (2005), they find forestry to have but a negligible feedback on the carbon market. Also, they find that forestry carbon offsets do not delay energy abatement. Conversely, Gitz et al. (2006) use a stochastic version of DIAM - a single region, least abatement costs model. They find, as in our case, a significant forestry-carbon market linkage.

This paper is divided as follows. Section 2 introduces both models and defines the coupling procedure. Section 3 presents numerical results, and Section 4 concludes.

\section{Models and coupling}

In this section, we present the two models that have been linked to analyze the role of forestry in contributing to the climate stabilization target of $550 \mathrm{ppmv} \mathrm{CO}_{2}$ only. For the energy-economy side we use the World Induced Technical Change Hybrid model (WITCH) (Bosetti et al., 2006), a recently designed hybrid integrated assessment model for 
climate change issues. As for the forestry part, we use a global timber model built upon Sohngen et al. (1999).

\subsection{The energy-economy-climate model}

WITCH is a regional integrated assessment model structured to provide normative information on the optimal responses of world economies to climate damages and to model the channels of transmission of climate policy to the economic system. It is a hybrid model because it combines features of both top-down and bottom-up modeling: the top-down component consists of an intertemporal optimal growth model in which the energy input of the aggregate production function has been expanded to give a bottom-up-like description of the energy sector. World countries are grouped in 12 regions that strategically interact following a game-theoretic structure. A climate module and a damage function provide the feedback on the economy of carbon dioxide emissions into the atmosphere. The WITCH top-down framework guarantees a coherent, fully intertemporal allocation of investments that have an impact on the level of mitigation-R\&D effort, investment in energy technologies, and fossil fuel expenditures. The regional specification of the model and the presence of strategic interaction among regions-through $\mathrm{CO}_{2}$, exhaustible natural resources, and technological spilloversallow us to account for the incentives to free-ride. By playing an open-loop Nash game, the investment strategies are optimized by taking into account both economic and environmental externalities. In WITCH, the energy sector has been detailed and allows a reasonable characterization of future energy and technological scenarios and an assessment of their compatibility with the goal of stabilizing GHG concentrations. Also, by endogenously modeling fuel (oil, coal, natural gas, uranium) prices, as well as the cost of storing the $\mathrm{CO}_{2}$ captured, the model can be used to evaluate the implication of mitigation policies on the energy system in all its components. Finally, technical change in WITCH is endogenous and is driven both by learning-by-doing (LbD) and by energy $\mathrm{R} \& \mathrm{D}$ investments. These two factors of technological improvements act through two different channels: LbD is specific to the power generation costs, while $R \& D$ affects the non-electric sector and the overall system energy efficiency.

In this paper, we focus on a stabilization policy of 550 ppmv. In order to do so, we perform a costeffectiveness analysis with a cap and trade policy instrument, and we set an equal per capita allocation system. We have an emission permit trading scheme that equalizes regional marginal abatement costs, creating a unique set of carbon prices. The model is solved to 2200 numerically in GAMS/CONOPT.

\subsection{The forestry model}

The forestry model is built upon the model described in Sohngen et al. (1999) and used by Sohngen and
Mendelsohn (2003) to analyze global sequestration potential. The model used in this analysis contains an expanded set of timber types, as described in Sohngen and Mendelsohn (2006). There are 146 distinct timber types in 13 regions: each of the 146 timber types modeled can be allocated into one of three general types of forest stocks. First, moderately valued forests, managed in optimal rotations, are located primarily in temperate regions. Second, high-value timber plantations are managed intensively. Subtropical plantations are grown in the southern United States (loblolly pine plantations), South America, southern Africa, the Iberian Peninsula, Indonesia, and Oceania (Australia and New Zealand). Finally, low-valued forests, managed lightly if at all, are located primarily in inaccessible regions of the boreal and tropical forests. The inaccessible forests are harvested only when timber prices exceed marginal access costs. The forestry model maximizes the net present value of net welfare in the forestry sector.

One important component of the costs of producing timber and carbon are land rental costs. The model accounts for these costs by incorporating a series of land rental functions for each timber type. The rental functions account for land competition between forestry and agriculture, although they are not presently responsive to price changes in agriculture (see Sohngen and Mendelsohn (2006) for additional discussion of the land rental functions). Incentives for carbon sequestration are incorporated into the forestry model by renting carbon. The price of energy abatement is the value of sequestering and holding a ton of carbon permanently. The rental value for holding a ton of carbon for a year is determined as the path of current and future rental values on that ton that is consistent with the price of energy abatement currently. One of the benefits of using the rental concept for carbon sequestration is that the carbon temporarily stored can be paid while it is stored, with no payments accruing when it is no longer stored (i.e., if forest land is converted to agriculture, or if timber is harvested, leaving the forest in a temporarily low-carbon state). Furthermore, renting carbon does not penalize current forestland owners by charging them for emissions. We do, however, account for long-term storage of carbon in wood products by paying the price of carbon for tons when they are stored permanently after harvest. For simplicity, in this analysis, we assume that $30 \%$ of harvested wood is stored permanently, following Winjum et al. (1998).

\subsection{Coupling}

Given the complexities of the two models used in this paper, we have integrated them via an iterative procedure. In order to do so, we have augmented both models so that they could incorporate results from the other, and have run subsequent iterations until convergence, as measured by a sufficiently small rate of variation of carbon prices. We define this as being less than a $5 \%$ average deviation in 
prices and quantities from one scenario to the next. As expected, the initial high responses of both models - in terms of adjustments of carbon prices to the quantities sequestered in forests and vice versa-gradually shrink, and an equilibrium is achieved after 11 iterations. For prices, the average deviation is $3 \%$ whereas for quantities it is $4 \%$. This way of interfacing two separate models is normally described as "soft link", and has been extensively used to couple energy system models and economic models to account for the mutual interactions between the energy sector and the whole economy.

To make the two models consistent, several additional adjustments were made. First, the different regions had to be matched. Coincidentally, the regional disaggregation is similar in the two cases-12 regions for the WITCH model, 13 for the forestry one - so that only minor adjustments were needed. Also, the WITCH model has 5-year time steps and the forestry model has 10 -year time steps. To link the two, we utilized prices at the 10 -year intervals provided by the WITCH model in the forestry model. We interpolated carbon sequestration rates between 10-year time increments from the forestry model when incorporating forest sequestration in the WITCH model. The forestry model has been augmented to comprise the time path of carbon prices, which is equalized across regions and given by the emissions permits prices of the cap and trade policy. To account for the non-permanence of the biological sequestration, carbon prices are transformed into annual storing values via rental rates. For more information, see Sohngen and Mendelsohn (2003). The energy-economyclimate model has been fed the carbon quantities sequestered by forests in each region by counting them in the carbon emission balances, as well as in the budget constraint - at the carbon price value.

\section{Results}

In this section, we report the numerical results of the contribution of forestry management in meeting a $\mathrm{CO}_{2}$ (only) stabilization policy of $550 \mathrm{ppmv}$ by 2100 . To give the feeling of what such a policy entails in terms of global warming mitigation, in Fig. 1 we show the time profile of carbon emissions for a business as usual (BaU) and a 550 ppmv policy resulting from using the WITCH with abatement only in the energy sector. In a no-policy scenario, emissions grow to $20 \mathrm{GtC}$ by the end of the century, whereas for the $550 \mathrm{ppmv}$ policy, emissions peak around 2050, falling by more than half after that with respect to $\mathrm{BaU}$. The $550 \mathrm{ppmv}$ policy reduces the carbon intensity in the economy considerably, and reduces the increase in global temperature by 2100 to $2.2^{\circ} \mathrm{C}$, from $2.9^{\circ} \mathrm{C}$ in the $\mathrm{BaU}$. Although this temperature is still higher than the IPCC advocated level of $2^{\circ} \mathrm{C}$, we concentrate on this target given its relevance, especially in terms of political feasibility.

We start by reporting the potential of forestry in contributing to the foreseen emission reductions, and then

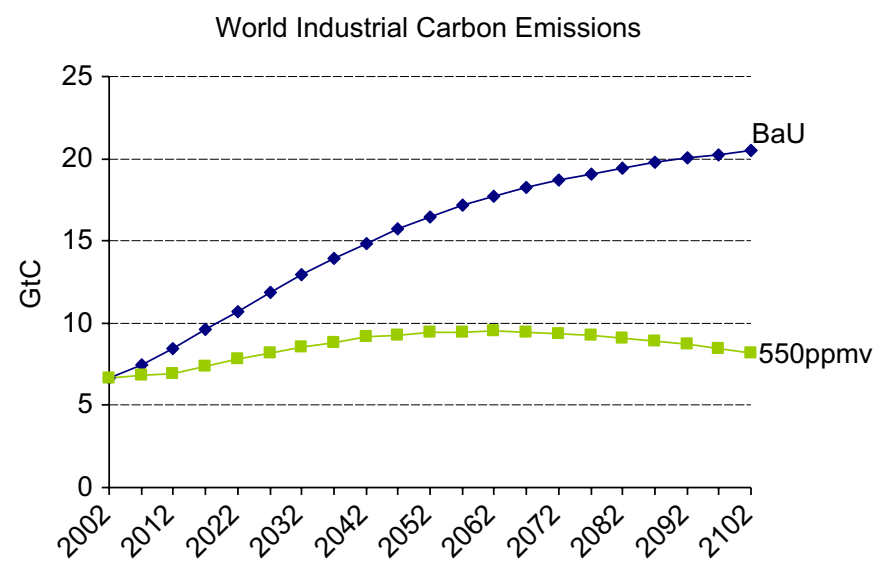

Fig. 1. Carbon emissions for business as usual and $550 \mathrm{ppmv}$ policy.

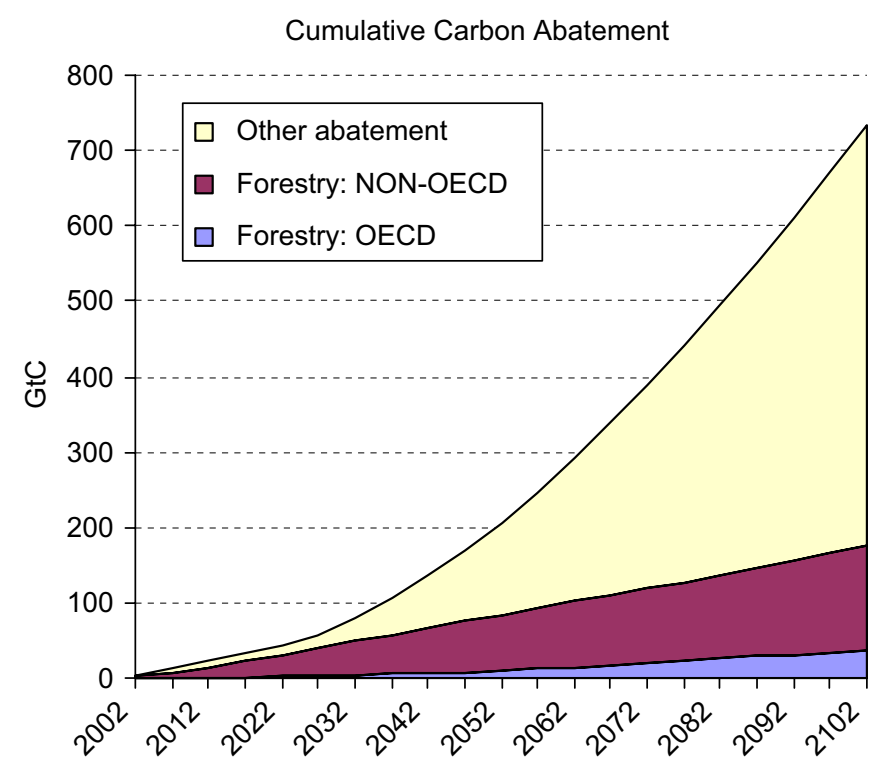

Fig. 2. Carbon abatement.

analyze the impacts on the carbon markets and the policy costs. Finally, we examine the retroactions on the energy abatement portfolio, with a particular look at the implications for induced technological change.

\subsection{Sequestration in forests}

Several studies in the forestry literature have estimated the sequestration potential for various given carbon prices, and most seem to agree that forestry can provide a significant share of abatement (Sedjo et al., 1995). As an example, it is worth remembering that tropical deforestation is a major source of GHG emissions, accounting for as much as $25 \%$ of global anthropogenic GHG emissions (Houghton, 2005).

Fig. 2 reports carbon abatement over the century accomplished by forestry in OECD and non-OECD countries vis-à-vis the overall abatement effort. The picture underlines an important role for biological sequestration: forests sequester around $75 \mathrm{GtC}$ cumulative to 2050 . 
This estimate is consistent with the results presented in earlier IPCC reports (see, for example, Watson et al., 2000) but of course there are costs associated with this forestry effort. Overall, forestry contributes to one-third of total abatement to 2050, or three wedges in the words of Pacala and Socolow (2004). After the peak in emissions in 2050, the share of forestry in total abatement starts to decline (from 2050 to 2100 it increases by only $10 \%$ in absolute values), given that the target gets more stringent and permanent emission cuts in the energy sector are called for.

The largest share of carbon sequestration occurs in nonOECD countries during the early part of the century (Table 1). Around $63 \%$ of all of the carbon sequestered from 2002 to 2052 of the stabilization scenario results from reductions in deforestation in just a few regions, namely Latin America, East Asia, and Sub-Saharan Africa. Most of this carbon is due to reductions in deforestation. While consideration of policies to reduce deforestation has been shunned in earlier negotiations related to the Kyoto Protocol, they recently received significant attention as a result of discussions at COP 11 in Montreal.

Focusing on Latin America, East Asia, and Sub-Saharan Africa, where the bulk of deforestation currently is occurring (FAO, 2005), around 10.7 million hectares of forestland are estimated to be lost each year (Table 2). The carbon incentives in the stabilization scenario would reduce these losses to around 5.9 million hectares per year during the first decade, and they would essentially halt net forest losses by 2022. While developing policies to reduce

Table 1

Regional forest carbon sequestration, 2025, 2055, 2095

\begin{tabular}{lrrr}
\hline & 2022 & 2052 & 2092 \\
\cline { 2 - 4 } & Mt C/yr & & \\
\hline OECD & & & \\
USA & 42 & 144 & 193 \\
OLDEURO & 37 & 82 & 132 \\
NEWEURO & 8 & 18 & 29 \\
CAJANZ & 31 & 115 & 125 \\
Total OECD & 118 & 360 & 479 \\
& & & \\
Non-OECD & 25 & 27 & 36 \\
KOSAU & 179 & 117 & 134 \\
TE & 73 & 49 & 31 \\
MENA & 270 & 175 & 32 \\
SSA & 34 & 57 & 431 \\
SASIA & 109 & 155 & 371 \\
China & 451 & 481 & 330 \\
EASIA & 391 & 326 & 1950 \\
LACA & 1649 & 1746 & 2429 \\
Total non-OECD & & & \\
Total global & 1766 & 2105 & $\$ 271$ \\
C price & $\$ 57$ & $\$ 113$ & \\
\hline CAJAZ: & & & \\
\hline
\end{tabular}

CAJANZ: Canada, Japan, and New Zealand. KOSAU: Korea, South Africa, and Australia. TE: Transition Economies. MENA: Middle East and North Africa. SSA: Sub-Saharan Africa. SASIA: India and South Asia. EASIA: South East Asia. LACA: Latin America and Caribbean. deforestation efficiently would undoubtedly be a difficult task, these results suggest that the economic value of making these changes could be substantial.

The overall size of the carbon program increases over the century as carbon prices rise. It increases in both the OECD and the non-OECD regions, but the largest percentage gains occur in the OECD, where the annual carbon sink rises from 118 to 479 million t C/yr. In most non-OECD regions, the strength of the sink is actually declining because there are no longer opportunities to reduce deforestation, and forest growth on large areas of land that were reforested during the century is starting to slow. The one outlier is China, where sequestration expands. Sequestration dynamics in China tend to be more similar to OECD countries because it has large areas of temperate forests that have long growing cycles.

By reducing deforestation and promoting afforestation, a forest carbon sequestration program as part of a stabilization strategy would have strong impacts on total forestland area in the world, increasing it by 1.1 billion hectares relative to the baseline, or around 0.7 billion hectares above the current area of forests (Table 3). The largest share of increased forest area occurs in non-OECD countries. The stabilization scenario has complex results on timber harvests and prices. Initially, timber is withheld from the market in order to provide relatively rapid forest carbon sequestration through aging timber. As a result, global harvests decline by $14.5 \%$ relative to the baseline in 2022. However, over the century, more forests imply a larger supply of timber. By 2092 timber harvests increase by $26 \%$. The changes in specific regions depend heavily on the types of forests (e.g., the growth function), the carbon in typical forests (e.g., biomass expansion factors), and economic conditions such as prices and costs. In contrast to the area changes, the largest increases in timber harvests (in relative and total terms) occur in OECD countries. OECD countries tend to have many species amenable to producing wood products.

\subsection{Optimal response of the carbon market}

We now focus on the general equilibrium effects of including forestry management as an abatement strategy. As a comprehensive measure of the influence of biological sequestration on the carbon market, we first examine what happens to the price of carbon when forestry is included into the policy. Fig. 3 shows the carbon price for the 550 ppmv policy throughout the century as found in the original version of the WITCH model (iter1), and after it has been coupled with the forestry model (iter11). Forest sinks substantially lower the cost of $\mathrm{CO}_{2}$, for example by $40 \%$ in 2050 , making a $550 \mathrm{ppmv}$ policy cost as much as a $600 \mathrm{pmmv}$ policy without including forestry. That is, carbon sinks achieve an additional 50 ppmv-or equivalently $\frac{1}{4}{ }^{\circ} \mathrm{C}$-in 2100 at no extra cost.

To corroborate the idea that forestry can alleviate the compliance to the 550 ppmv target, in Fig. 4 we show the 
Table 2

Net land area change in regions currently undergoing substantial deforestation, in million hectares per year

\begin{tabular}{|c|c|c|c|c|}
\hline & \multirow[b]{2}{*}{ FAO (2000-2005) } & \multicolumn{3}{|c|}{ Projected for } \\
\hline & & 2002-2012 & 2012-2022 & $2022-2032$ \\
\hline Latin and Central America & -4.7 & -2.3 & -0.9 & 0.2 \\
\hline East Asia & -2.8 & -1.2 & -0.4 & -0.1 \\
\hline Sub-Saharan Africa & -3.2 & -2.4 & -0.1 & 0.0 \\
\hline Total & -10.7 & -5.9 & -1.4 & 0.1 \\
\hline
\end{tabular}

Table 3

Change in forestland area and change in annual timber harvests compared to the baseline

\begin{tabular}{|c|c|c|c|c|c|c|}
\hline & 2022 & 2052 & 2092 & 2022 & 2052 & 2092 \\
\hline & \multicolumn{3}{|c|}{ Million hectares } & \multicolumn{3}{|c|}{$\%$ Change in annual harvest } \\
\hline \multicolumn{7}{|l|}{ OECD } \\
\hline USA & 1.5 & 23.1 & 94.2 & 1.2 & -9.0 & 48.5 \\
\hline OLDEURO & 11.5 & 34.9 & 51.9 & -5.3 & 12.1 & 0.3 \\
\hline NEWEURO & 2.6 & 7.8 & 11.6 & -5.3 & 12.1 & 0.3 \\
\hline CAJANZ & -4.0 & 24.5 & 99.0 & -3.8 & -3.3 & 167.3 \\
\hline Total OECD & 11.6 & 90.3 & 256.7 & -3.3 & 3.0 & 54.1 \\
\hline \multicolumn{7}{|l|}{ Non-OECD } \\
\hline KOSAU & 5.1 & 17.7 & 49.1 & 11.3 & 34.5 & 42.1 \\
\hline $\mathrm{TE}$ & 19.0 & 52.2 & 102.7 & -20.8 & 8.9 & -26.1 \\
\hline MENA & 10.3 & 24.9 & 38.4 & -63.9 & -45.9 & -6.7 \\
\hline SSA & 37.2 & 90.7 & 137.0 & -70.1 & -52.9 & -9.0 \\
\hline SASIA & 5.2 & 18.8 & 32.3 & -3.7 & -3.9 & 13.0 \\
\hline China & 8.6 & 41.9 & 115.4 & -20.1 & 0.0 & -98.8 \\
\hline EASIA & 25.6 & 66.0 & 111.9 & -63.3 & -57.2 & -48.9 \\
\hline LACA & 42.9 & 129.3 & 262.4 & -24.8 & -7.1 & 15.5 \\
\hline Total non-OECD & 153.8 & 441.5 & 849.2 & $-31.9 \%$ & $-15.4 \%$ & $-14.9 \%$ \\
\hline Total & 165.4 & 531.8 & 1105.9 & $-14.5 \%$ & $-3.3 \%$ & $25.9 \%$ \\
\hline
\end{tabular}

CAJANZ: Canada, Japan, and New Zealand. KOSAU: Korea, South Africa, and Australia. TE: Transition Economies. MENA: Middle East and North Africa. SSA: Sub-Saharan Africa. SASIA: India and South Asia. EASIA: South East Asia. LACA: Latin America and Caribbean.

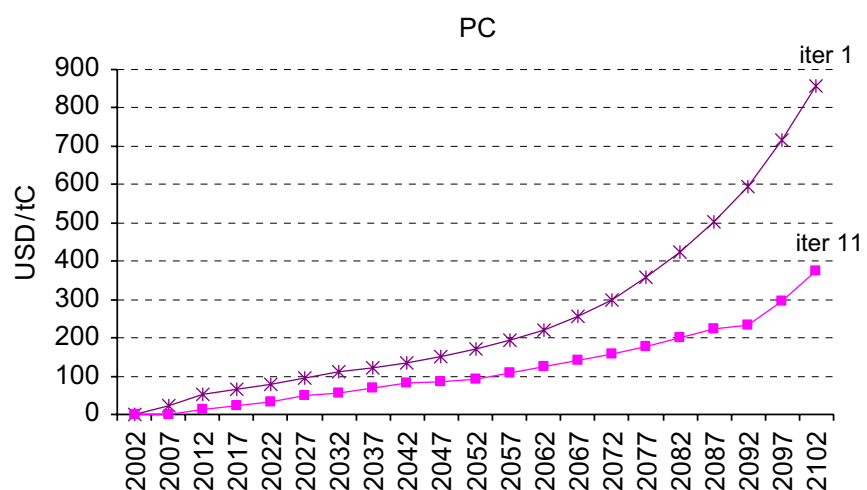

Fig. 3. Price of carbon with (iter11) and without (iter1) forestry.

policy costs with and without forestry. Again, forest sinks are shown to decrease policy costs: in particular, the policy burden is reduced and shifted ahead in the period to 2050 ,

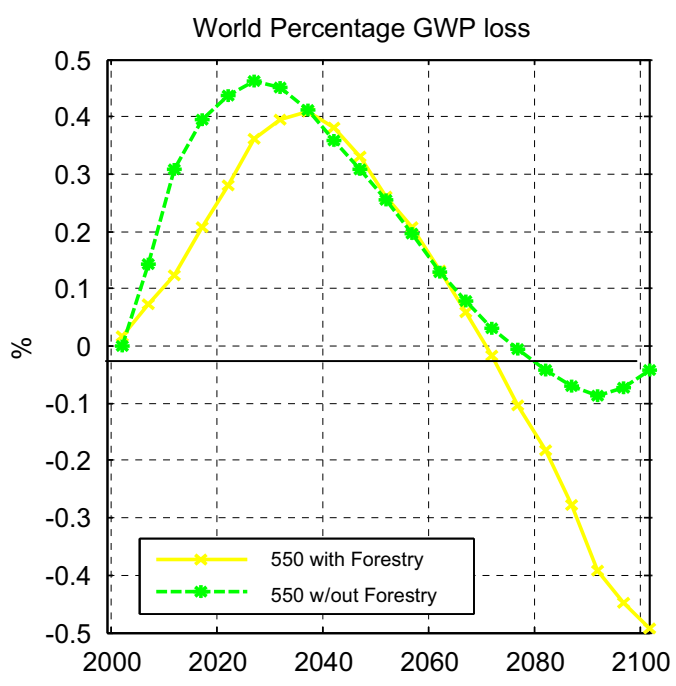

Fig. 4. Policy costs with and without forestry.

when the main action is via avoided deforestation. After 2070 the policy-induced benefits from avoided climate damages outweigh the costs of reducing emissions, and this effect is reinforced when forestry is an available mitigation option. All in all, the world policy cost in net present value decreases from $0.2 \%$ without forestry to $0.1 \%$ with forestry. This corresponds to a net present value saving to 2100 of almost $\$ 3.0$ trillion (USD), which is nearly three times the present value cost of adding the forestry program of $\$ 1.1$ trillion (USD).

One might wonder what are the distributional effects of including forestry for different regions. Two competing effects are at stake: on the one hand, forestry will benefit developing countries that are rich in tropical forests, given the role of avoided deforestation. On the other hand, the lower price of carbon will benefit countries that buy carbon market permits, and disadvantage sellers. Ultimately, the distributional effects will depend on the emissions allocation scheme adopted in the policy. For example, if one assumes that emissions are allocated based on an equal per capita rule, as we do in this paper, most of the emissions reductions are borne by the developed countries. Lower carbon prices with forestry included in the stabilization policy improve welfare in OECD countries by reducing their costs (from an undiscounted loss of $0.6 \%$ without 
forestry to $0.2 \%$ with forestry). On the contrary, nonOECD countries tend to be carbon permit sellers, and they have lower revenues when forestry is included as an option, although the difference in revenues is fairly small (from an undiscounted gain of $0.38 \%$ without forestry to $0.27 \%$ with forestry). It is worth noting that a different allowances allocation scheme would have changed the distributional results, though it would not have any impact on the carbon prices as they are determined by the world marginal abatement costs.

\subsection{Implications for energy abatement and technological change}

An issue that has played a political relevance in the decision to keep forestry outside the Kyoto Protocol is the danger that the emissions constraint on the energy system might be relaxed too much: the deployment of clean technologies that can reduce emissions permanently might be delayed, and accordingly the investments in innovation that are needed to make new technologies competitive. Given the low turnover of energy capital stock, as well as the lengthy process before commercialization of advanced technologies, this is a justified reason of concern. The energy sector description and the endogenous technological change feature of the WITCH model allow us to check for the variations in energy abatement due to forestry.

In Fig. 5 we show the evolution of the world primary energy intensity, an aggregate indicator that summarizes the energy efficiency of the economy. Results are presented for the $\mathrm{BaU}$ scenario, and the $550 \mathrm{ppmv}$ policy with and without forestry. As expected, the climate target induces more reductions in energy intensity with respect to the $\mathrm{BaU}$ scenario. However, this reduction is more moderate when we include the forestry abatement option: the energy

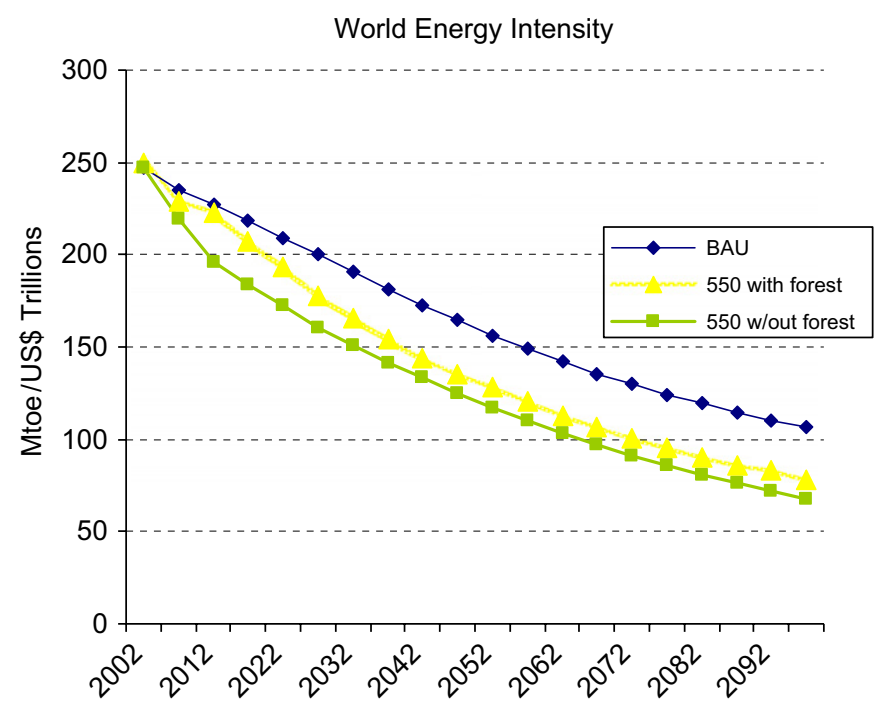

Fig. 5. Energy intensity of the economy.
LbD: Investment cost of wind \& solar plants wrt to BAU

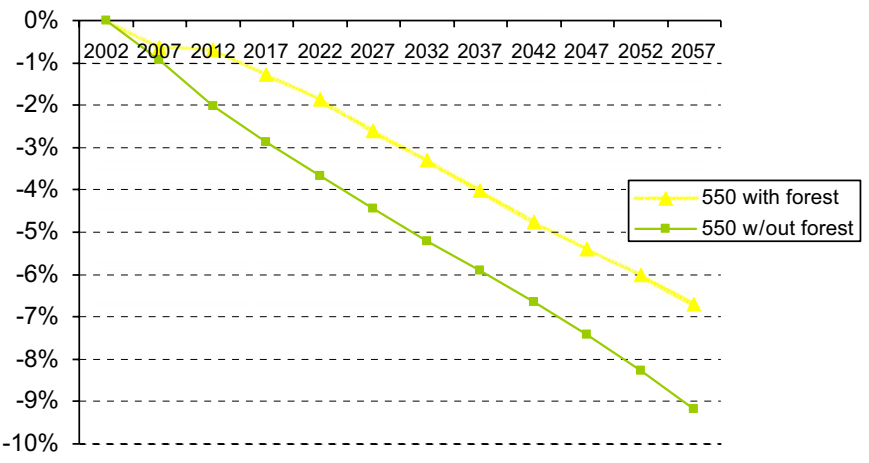

Fig. 6. Induced technological change with and without forestry.

intensity remains close to the $\mathrm{BaU}$ in the first $2-3$ decades of this century, when avoided deforestation is significantly contributing to abatement, and then approaches the noforestry path, as the emissions cuts in the energy sector become more predominant. We thus provide evidence of a delay in energy abatement, though limited to the very first part of the century. For example, the initial deployment of coal power plants with carbon capture and storage is postponed from 2015 (without forestry) to 2030 (with forestry). Similarly, the share of nuclear power is lower with forestry. Such a setback of low-carbon technologies can be seen either as harmful for the global warming cause or optimistically as a bridge solution in the wait to develop more consolidated, yet currently uneconomical, technologies.

We can try to answer this question by looking at what happens to the policy-induced technological change in the model. As mentioned in Section 2.2, WITCH features endogenous technological change via both LbD and energy R\&D. In Fig. 6 we show the forestry inclusion implications for LbD: we plot the percentage variations in the investment costs of wind and solar power plants with respect to the $\mathrm{BaU}$ case, either with or without forestry. Forest sinks hamper the capacity of the $550 \mathrm{ppmv}$ policy to induce technological change, as testified by the lower decrease in renewable costs due to the lower capacity deployment. Also, energy R\&D investments are decreased by forestry, by roughly $10 \%$ (not shown). Although these are not vast variations in absolute figures, technological innovation could play a crucial role in hedging against possible future revisions of the climate targets, for example in case more pessimistic evidence about global warming emerges. Inevitably, in meeting given emission caps forestry crowds out other abatement; accompanying technological policies might be desirable to ensure a contemporaneous emergence of innovative technologies.

\section{Conclusions}

This paper evaluates the potential of forest sequestration within the context of stabilizing future concentrations of 
atmospheric carbon at $550 \mathrm{ppmv} \mathrm{CO}_{2}$, and it assesses the feedback of forest sequestration on "traditional" energy abatement options. Although numerous studies have estimated the mitigation contribution of forest sinks, understanding how forest sequestration integrates with other climate change options has received little attention. Contemporaneous determination of carbon prices and sequestration in forests, and on the general equilibrium consequences, is thus a largely unexplored area of research. The current paper is a significant contribution as it provides insights of the effects of including forest management on the optimal carbon market responses, the energy technology evolution, and induced technological change.

Results show that forestry is an important abatement option, and that its inclusion into an international policy agreement can have a profound effect on the global costs of a climate policy, allowing a free saving of $50 \mathrm{ppmv}$ in 2100 , corresponding to $\frac{1}{4}{ }^{\circ} \mathrm{C}$. In particular, we find that the total costs of the forestry program are $\$ 1.1$ trillion (USD) and the benefits, in terms of additional gross world product relative to meeting the same carbon constraint without forestry, are $\$ 3.0$ trillion (USD). Forest sequestration actions in the first half of the century, mainly from avoiding deforestation, could contribute one-third of total abatement effort, and could provide additional benefits throughout the entire century. Forest sinks have the potential to reduce the price of traded carbon permits, and the overall cost of the policy in terms of income losses, by half. However, in meeting the emissions reductions target, forestry crowds out some of the abatement in the energy sector for the first 2-3 decades. For example, deployment a potentially relevant energy abatement technology such as carbon capture and storage is delayed by 15 years. Policy-induced technological change in clean technologies such as renewables power generation is also reduced. Policy makers should consider developing targeted policies to help achieve the technological advancement to hedge against unknown risks, but they can make substantial headway towards achieving climate stabilization now with forest carbon sequestration.

These results provide a first step towards fuller consideration of land-based carbon sequestration in energy models. Future work should consider several improvements over this analysis. First, for example, future analysis should more carefully consider competition with agriculture and other land uses. Sequestration or abatement in the agricultural sector could provide important competing options for meeting stabilization targets, and thus are important to consider as well. Second, the endogenous effects of an increase in global temperature on the capacity of forests to sequester carbon can provide a more complete assessment of the problem. Third, biomass energy provides an additional competing land use that could have implications for these results.

\section{References}

Bosetti, V., Carraro, C., Galeotti, M., Massetti, E., Tavoni, M., 2006. WITCH: a world induced technical change hybrid model. The Energy Journal, Special Issue. Hybrid Modeling of Energy-Environment Policies: Reconciling Bottom-up and Top-down, pp. 13-38.

FAO, 2005. Global Forest Resources Assessment 2005. FAO, Forestry Paper 147.

Gitz, V., Hourcade, J.C., Ciais, P., 2006. The timing of biological carbon sequestration and carbon abatement in the energy sector under optimal strategies against climate risks. The Energy Journal 27 (3), 113-133.

Goulder, L.H., Mathai, K., 2000. Optimal $\mathrm{CO}_{2}$ abatement in the presence of induced technological change. Journal of Environmental Economics and Management 39, 1-38.

Houghton, R.A., 2005. Tropical deforestation as a source of greenhouse gas emissions. In: Mountinho, P., Schwartzman, S. (Eds.), Tropical Deforestation and Climate Change. IPAM: Belem, Brazil and Environmental Defense, Washington, DC, pp. 13-21.

International Panel on Climate Change (IPCC), 2001. The Scientific Basis, Cubasch et al., Contribution of Working Group I the Third Assessment Report of the Intergovernmental Panel on Climate Change. In: Houghton, et al. (Eds.), Cambridge University Press, Cambridge, UK.

Metz, B., Davidson, O., Swart, R., Pan, J., 2001. Climate Change 2001: Mitigation. Cambridge University Press, Cambridge, UK.

Moutinho, P., Santilli, M., Schwartzman, S., Rodrigues, L., 2005. Why ignore tropical deforestation? A proposal for including forest conservation in the Kyoto Protocol. Unasylva, International Journal of Forestry and Forest Industries 56 (222), 27-30.

Nordhaus, W., Boyer, J., 2000. Warming the World: Economic Models of Global Warming. MIT Press, Cambridge, MA.

Pacala, S., Socolow, R., 2004. Stabilization wedges: solving the climate problem for the next 50 years with current technologies. Science 305, 968-972.

Richards, K.R., Stokes, C., 2004. A review of forest carbon sequestration cost studies: a dozen years of research. Climatic Change 63 (1-2), 1-48.

Rose, S., Ahammad, H., Eickhout, B., Fisher, B., Kurosawa, A., Rao, S., Riahi, K., van Vuuren, D., 2006. Land in climate stabilization modeling. Energy Modeling Forum Report, Stanford University 〈www.stanford.edu/group/EMF/projects/group21/EMF21sinkspagenew. htm2006 .

Sedjo, R.A., Visniewski, J., Sample, A.V., Kinsman, J.D., 1995. The economics of managing carbon via forestry: assessment of existing studies. Environmental and Resource Economics 6, 139-165.

Sohngen, B., Mendelsohn, R., 2003. An optimal control model of forest carbon sequestration. American Journal of Agricultural Economics 85 (2), 448-457.

Sohngen, B., Mendelsohn, R., 2006. A sensitivity analysis of carbon sequestration. In: Schlesinger, M. (Ed.), Human-Induced Climate Change: An Interdisciplinary Assessment. Cambridge University Press, Cambridge.

Sohngen, B., Mendelsohn, R., Sedjo, R., 1999. Forest management, conservation, and global timber markets. American Journal of Agricultural Economics 81 (1), 1-13.

van't Veld, K., Plantinga, A., 2005. Carbon sequestration or abatement? The effect of rising carbon prices on the optimal portfolio of greenhouse-gas mitigation strategies. Journal of Environmental Economics and Management 50, 59-81.

Watson, R.T., Noble, I.R., Bolin, B., Ravindranath, N.H., Verardo, D.J., Dokken, D.J., 2000. Land Use, Land-Use Change, and Forestry. Cambridge University Press, Cambridge, UK.

Winjum, J.K., Brown, S., Schlamadinger, B., 1998. Forest harvests and wood products: sources and sinks of atmospheric carbon dioxide. Forest Science 44, 272-284. 